\title{
ANALISIS MPN (MOST PROBABLE NUMBER) COLIFORM PADA AIR SUMUR GALI PENDUDUK YANG BERMUKIM DI SEKITAR KANAL KELURAHAN MATAALLO KECAMATAN BAJENG KABUPATEN GOWA
}

\author{
Sitti Hadijah \\ Jurusan Analis Kesehatan Poltekkes Makassar \\ Koresponden: Shitaku2975@gmail.com
}

\begin{abstract}
ABSTRAK
Penelitian ini di latar belakangi oleh meningkatnya kejadian diare beberapa tahun terakhir. Dimana Gambaran fisik sumur yang ada di Kelurahan Mataallo Kecamatan Bajeng Kabupaten Gowa yaitu sumur berdekatan dengan wc, septik tank dan kanal. dimana jarak sumur $<5$ meter dari pembuangan tinja dan $<11$ meter dari kanal. sehingga air yang digunakan untuk keperluan sehari-hari seperti untuk minum, memasak, mencuci dan mandi dapat di cemari oleh berbagai jenis bakteri penyebab penyakit. Tujuan penelitian ini adalah untuk mengetahui dan menentukan jumlah MPN Coliform pada air sumur gali penduduk yang bermukim di sekitar kanal Kelurahan Mataallo Kecamatan Bajeng Kabupaten Gowa. Jenis penelitian ini merupakan penelitian observasi laboratorik dengan teknik pengambilan sampel secara purposive sampling sebanyak 10 sampel. Hasil penelitian menunjukkan nilai yang bervariasi yaitu $110 \mathrm{MPN} / 100 \mathrm{ml}, 180 \mathrm{MPN} / 100 \mathrm{ml}, 280 \mathrm{MPN} / 100 \mathrm{ml}, 350$ MPN/100ml, 920 MPN/100 ml dan 1600 MPN/100 ml air. Dan kesimpulannya adalah air sumur gali penduduk yang bermukim disekitar kanal Kelurahan Mataallo Kecamatan Bajeng Kabupaten Gowa tidak memenuhi standar yang telah dikeluarkan oleh permenkes No.492/MenKes/PER/IV/2010 yaitu 0/100 ml air.
\end{abstract}

Kata Kunci : MPN (Most Probable Number), Air sumur Gali

\section{PENDAHULUAN}

Jumlah penyakit yang setiap tahun terjadi masih tinggi menandakan bahwa keadaan air yang dipergunakan sehari-hari dalam keadaan tercemar. Beberapa penyakit diare dan kulit yang masih sering terjadi di indonesia. Penyebaran tersebut dapat melalui air danau, air sungai, air rawa, air sawah, air sumur, air pompa, air pipa, air laut, air buangan dan lain sebagainya (Lud waluyo, 2009).

Air merupakan salah satu jenis sumber daya alam yang diperlukan untuk mendukung kehidupan oleh hampir semua makhluk hidup yang mendiami permukaan bumi. Oleh sebab itu, keberadaan sumber daya air harus dilindungi agar tetap dapat diandalkan untuk mendukung kehidupan baik bagi manusia maupun makhluk hidup lainnya (Mukhlis Akhadi, 2014).

Coliform adalah kelompok bakteri indikator untuk menentukan kualitas atau mutu dari lingkungan air, tanah atau makanan. Ciri-ciri dari bakteri coliform adalah merupakan Gram negatif, mikroba tidak berspora, 
mampu memfermentasi laktosa menjadi gas dan asam pada suhu 35$37^{\circ} \mathrm{C}$ (sinta dkk 2010).

Bakteri coliform dapat dibedakan atas 2 grup yaitu coliform fekal, misalnya Escherichia coli dan coliform non fekal misalnya Enterobacter aerogenes. Kebanyakan golongan bakteri ini juga menunjukkan adanya bakteri patogen lain (Fardiaz, 1993).

Dalam air, bakteri coliform menghasilkan zat ethionine yang dapat menyebabkan kanker. Bakteri-bakteri ini juga memproduksi bermacammacam racun seperti indol dan skatol yang dapat menimbulkan penyakit bila berlebih didalam tubuh. Jenis bakteri coliform tertentu misalnya Escherichia coli O:157:H:7, bersifat patogen dan juga dapat menyebabkan diare atau diare berdarah, kram perut, mual dan rasa tidak enak badan (Suripin, 2004).

Air sumur, meskipun juga tergantung lingkungannya, pada umumnya lebih bersih daripada air permukaan, karena telah tersaring oleh lapisan-lapisan tanah yang dilewatinya. Untuk air minum misalnya, bakteri coli harus kurang dari satu atau tidak ada sama sekali, kalau kualitas air tersebut termasuk yang betul-betul memenuhi syarat (Unus Suriawiria, 2005). Data yang didapatkan dari Kelurahan Mataallo Kecamatan Bajeng Kabupaten Gowa yaitu masyarakat yang mengalami diare meningkat 4 tahun terakhir. Dimana pada tahun 2012 sebanyak 23 orang, tahun 2013 sebanyak 34 orang, tahun 2014 sebanyak 38 orang dan tahun 2015 sebanyak 51 orang. Sedangkan pada bulan januari sampai juni 2016 masyarakat yang mengalami diare sebanyak 13 orang.

Pencemaran penyakit air biasanya masuk lewat tinja, kotoran hewan, sampah, air kencing, dahak, ludah, ekskresi luka kedalam badan air. Pencemaran kedalam badan air dapat juga secara tidak sengaja, seperti masuknya kembali air buangan kedalam sumur, keadaan pipa air yang bocor pada tempat yang kotor dan lain sebagainya (Lud Waluyo, 2009). Lingkungan tercemar oleh bakteri coliform menentukan apakah kualitas bahan berupa air, tanah, atau bahan makanan layak untuk dikonsumsi atau tidak. Untuk mengujinya dapat menggunakan suatu test dengan metode jumlah perkiraan terdekat atau Most Probable Number (MPN) (Arif sumantri, 2010).

Untuk menghindari pencemaran langsung harus memperhatikan jarak sumur gali minimal 11 meter dari sumber pencemar antara lain : jamban, air kotor, air comberan, tempat pembuangan sampah, kandang ternak dan lain-lain (http://Noviaki.10jambi.Wordpress.co $\mathrm{m})$.

Gambaran fisik sumur yang ada di Kelurahan Mataallo Kecamatan Bajeng Kabupaten Gowa yaitu sumur berada didekat jamban, septic tank, limbah rumah tangga, dan kanal. Dimana jarak sumur $<5$ meter dari pembuangan tinja dan $<11$ meter dari kanal. Sehingga air yang digunakan untuk keperluan sehari-hari, seperti untuk minum, masak, mencuci, dan mandi, dapat dicemari oleh berbagai jenis bakteri penyebab penyakit.

Mencermati berbagai data diatas, maka peneliti tertarik untuk menganalisa coliform pada air sumur 
gali penduduk yang bermukim disekitar kanal Kelurahan Mataallo Kecamatan Bajeng Kabupaten Gowa. Tujuan penelitian adalah untuk mengetahui ada tidaknya coliform pada air sumur gali penduduk yang bermukim disekitar kanal Kelurahan Mataallo Kecamatan Bajeng Kabupaten Gowa

\section{METODE}

\section{Jenis, Waktu dan Lokasi Penelitian}

Jenis penelitian ini dilakukan secara observasional laboratorik dimana akan di analisa MPN coliform pada air sumur gali pada penduduk yang bermukim di sekitar kanal Kelurahan Mataallo Kecamatan Bajeng Kabupaten Gowa. Waktu penelitian dilaksanakan pada bulan Juni 2016. Lokasi penelitian direncanakan di laboratorium Bakteriologi Analis Kesehatan Politeknik Kesehatan Makassar.

\section{Populasi penelitian, sampel penelitian, teknik pengambilan sampel, alat dan bahan.}

Populasi penelitian ini adalah semua sumur gali pada penduduk yang bermukim di sekitar kanal Kelurahan Mataallo Kecamatan Bajeng Kabupaten Gowa. Sampel penelitian ini adalah air sumur gali pada penduduk yang bermukim di sekitar kanal Kelurahan Mataallo Kecamatan Bajeng Kabupaten Gowa. Besar sampel yang digunakan sebanyak 10 sampel air sumur gali pada penduduk yang bermukim di sekitar kanal Kelurahan Mataallo Kecamatan Bajeng Kabupaten Gowa. Teknik pengambilan sampel pada penelitian ini adalah secara porposive sampling yaitu pengambilan sampel sesuai dengan kriteria yang telah ditentukan.
Dengan kriteria sampel yaitu sumur terbuka, jarak sumur dengan sumber pencemaran < 11 meter, pembuatan sumur gali yang belum memenuhi syarat. Alat yang digunakandalam penelitian ini adalah Botol steril, tabung reaksi steril, erlenmeyer 250 $\mathrm{ml}$, beaker glass, tabung durham, autoclave, sendok/tangkai pengaduk, rak tabung, pipet ukur $(10 \mathrm{ml}$ dan 1 $\mathrm{ml}$ ), pipet tetes, bunsen, timbangan, oven, inkubator, ose bulat, tali pengikat, kertas pembungkus, korek api, label, pulpen, kapas dan cool box. Bahan yang digunakan dalam penelitian ini adalah Sampel air sumur, alkohol 70\%, aquades, media LB (Lactosa Broth) 1,5\% dan 0,5\%, media BGLB (Brilliant Green Bile Lactosa Broth).

\section{Prosedur Penelitian}

Metode:

Metode yang digunakan dalam penelitian ini adalah pemeriksaan laboratorium dengan penentuan jumlah bakteri metode Most Probable Number (MPN) coliform atau perkiraan jumlah kuman terdekat dengan memakai porsi 5-5-5.

Prinsip:

Coliform memfermentasikan laktosa yang ditandai dengan terbentuknya gas pada media LB (Lactosa Broth) dan BGLB (Brilliant Green Bile Lactosa Broth). Nilai most probable number (MPN) dihitung berdasarkan jumlah tabung yang positif yang disesuaikan dengan nilai tabel Most Probable Number (MPN).

Cara kerja:

Pra analitik (Pusat Laboratorium Kesehatan, 1991)

Sterilisasi alat dilakukan dengan Menyiapkan alat-alat yang akan di sterilisasikan, kemudian Alat (alat 
gelas) dibungkus dengan menggunakan kertas yang bersih secara rapat-rapat. Setelah alat-alat dibungkus, kemudian dimasukkan kedalam oven bersuhu $108^{\circ} \mathrm{C}$ selama dua jam. Sterilisasi bahan dilakukan dengan Memasukkan bahan yang akan di sterilkan kedalam autoclave kemudian Disterilisasi selama 15 menit pada suhu $121^{\circ} \mathrm{C}$.

Persiapan wadah:

Untuk sampel air sumur yaitu pada bagian mulut botol diikatkan tali dengan panjang 20 meter. Sebelum disterilisasi, semua botol (beserta tali dan pemberatnya) dibungkus dengan kertas coklat atau kertas timah, dan diikat dengan benang lalu Di sterilisasi dalam autoclave selama 30 menit pada $120^{\circ} \mathrm{C}$. Cara pengambilan sampel air sumur gali, Pengambilan specimen air harus dilakukan secara steril guna memastikan tidak terdapatnya organisme yang mengkontaminasi. Membuka bungkus botol yang telah steril, bilas tangan dengan ethanol $70 \%$, kemudian buka tutup botol dan letakkan diatas bungkus botol yang steril tadi. Dengan posisi mulut botol menghadap keatas, diulurkan botol tersebut kedalam sumur secara perlahan-lahan jangan sampai botol tersebut menyentuh dinding sumur. Celupkan seluruh permukaan botol kedalam air sumur hingga mencapai pertengahan sumur. Menarik botol yang telah terisi penuh dengan air secara perlahan-lahan, buang $1 / 4$ bagian dari air yang ada dalam botol tersebut. Menutup kembali botol tersebut, dibungkus dengan kertas steril tadi dan mengikat dengan tali pada bagian leher botol kemudian beri label.

Pengiriman spesimen, Pengiriman spesimen dilaksanakan secepatnya dalam waktu kurang dari 24 jam. Bila perjalanan diperkirakan akan memakan waktu lebih dari tiga jam, spesimen harus dikirim dalam suasana dingin, pada suhu $4-10^{\circ} \mathrm{C}$. Sampel air yang akan dikirim harus dikemas terlebih dahulu.

Analitik (Fardiaz, 1993)

Tes pendahuluan:

Disiapkan satu seri tabung uji (seri 555) lalu diberi label : lima tabung berisi LB konsentrasi 1,5\%-10 ml sampel air, lima tabung berisi LB konsentrasi 0,5\%-1 ml sampel air dan lima tabung berisi LB konsentrasi 0,5\%-0,1 ml sampel air. Lalu dihomogenkan sampel air dengan dikocok kuat setelah itu mulut botol disterilkan dengan melewatkan mulut botol pada nyala api spiritus. Kemudian dipindahkan $10 \mathrm{ml}$ sampel air kedalam lima tabung yang berlabel LB konsentrasi $1,5 \%$ dengan menggunakan pipet $10 \mathrm{ml}$. Lalu dipindahkan $1 \mathrm{ml}$ sampel air kedalam lima tabung yang berlabel LB konsentrasi $\quad 0,5 \%$ dengan menggunakan pipet $1 \mathrm{ml}$. Dan terakhir dipindahkan $0,1 \mathrm{ml}$ sampel air kedalam lima tabung yang berlabel LB konsentrasi $0,5 \%$ dengan menggunakan pipet $1 \mathrm{ml}$. kemudian menginkubasi selama 18-24 jam pada suhu $37^{\circ} \mathrm{C}$, jika belum ada pertumbuhan (kekeruhan dan terdapat gas dalam tabung durham) maka inkubasi dilanjutkan sampai 48 jam lalu diamati semua tabung LB (Lactosa Broth) yang memperlihatkan kekeruhan dan terbentuknya gas dalam tabung durham.

Tes penegasan BGLB:

Tabung yang positif selanjutnya diinokulasi pada media BGLB lalu diinkubasi pada suhu $37^{\circ} \mathrm{C}$ selama 24 
jam. Diamati tabung positif pada media BGLB yang ditandai dengan terbentuknya kekeruhan dan gas dalam tabung durham.

Pasca analitik: Menghitung jumlah MPN coliform menggunakan tabel seri 555

\section{Analisa Data}

Pada penelitian ini data yang diperoleh dari hasil pemeriksaan dan pengamatan disajikan dalam bentuk tabel kemudian dianalisa secara deskriptif dan dibahas secara narasi.

\section{HASIL}

Berdasarkan penelitian yang telah dilakukan di Laboratorium Bakteriologi Jurusan Analis Kesehatan Poltekkes Kemenkes Makassar yang di laksanakan mulai tanggal 14 - 26 Juli 2016 sebanyak 10 sampel. Penelitian ini menggunakan Metode MPN Coliform yang dipakai untuk menentukan perkiraan jumlah terdekat kuman pada air sumur gali penduduk yang bermukim di sekitar kanal Kelurahan Mataallo Kecamatan Bajeng Kabupaten Gowa, diperoleh hasil sebagai berikut :

Tabel 1. Hasil Pemeriksaan Air Sumur Gali Penduduk yang Bermukim di Sekitar Kanal di Laboratorium Bakteriologi Analis Kesehatan Politeknik Kesehatan Makassar

\begin{tabular}{cccccccc}
\hline Kode & \multicolumn{3}{c}{ Tes Pendahuluan } & \multicolumn{3}{c}{ Tes Penegasan } & Nilai \\
\cline { 2 - 6 } Sampel & $\mathbf{1 0 m l}$ & $\mathbf{1 m l}$ & $\mathbf{0 , 1 m l}$ & $\mathbf{1 0 m l}$ & $\mathbf{1 m l}$ & $\mathbf{0 , 1 m l}$ & MPN/100ml \\
\hline Sampel 1 & $5 / 5$ & $5 / 5$ & $5 / 5$ & $5 / 5$ & $5 / 5$ & $3 / 5$ & 920 \\
Sampel 2 & $5 / 5$ & $5 / 5$ & $5 / 5$ & $5 / 5$ & $5 / 5$ & $4 / 5$ & 1600 \\
Sampel 3 & $5 / 5$ & $5 / 5$ & $5 / 5$ & $5 / 5$ & $3 / 5$ & $3 / 5$ & 180 \\
Sampel 4 & $5 / 5$ & $5 / 5$ & $5 / 5$ & $5 / 5$ & $5 / 5$ & $4 / 5$ & 1600 \\
Sampel 5 & $5 / 5$ & $5 / 5$ & $5 / 5$ & $5 / 5$ & $5 / 5$ & $3 / 5$ & 920 \\
Sampel 6 & $5 / 5$ & $5 / 5$ & $5 / 5$ & $5 / 5$ & $4 / 5$ & $4 / 5$ & 350 \\
Sampel 7 & $5 / 5$ & $5 / 5$ & $4 / 5$ & $5 / 5$ & $5 / 5$ & $4 / 5$ & 1600 \\
Sampel 8 & $5 / 5$ & $5 / 5$ & $5 / 5$ & $5 / 5$ & $5 / 5$ & $4 / 5$ & 1600 \\
Sampel 9 & $5 / 5$ & $5 / 5$ & $4 / 5$ & $5 / 5$ & $4 / 5$ & $3 / 5$ & 280 \\
Sampel 10 & $5 / 5$ & $3 / 5$ & $2 / 5$ & $5 / 5$ & $3 / 5$ & $1 / 5$ & 110 \\
\hline
\end{tabular}

Standar Permenkes No. 492/MenKes/PER/IV/2010 yaitu 0/100 ml air

Sumber : Data Primer 2016

Berdasarkan hasil pemeriksaan pada air sumur gali penduduk yang bermukim di sekitar kanal Kelurahan Mataallo Kecamatan Bajeng Kabupaten Gowa didapatkan hasil yang bervariasi yaitu pada sampel 1 dan 5 sebanyak $920 \mathrm{MPN} / 100 \mathrm{ml}$ air, sampel 2,4,7 dan 8 sebanyak 1600 MPN/100 ml air, sampel 3 sebanyak $180 \mathrm{MPN} / 100 \mathrm{ml}$ air, sampel 6 sebanyak $350 \mathrm{MPN} / 100 \mathrm{ml}$ air, sampel 9 sebanyak $280 \mathrm{MPN} / 100 \mathrm{ml}$ air dan sampel 10 sebanyak 110 MPN/100 ml air. Seluruh sampel menunjukkan hasil diatas ambang baku mutu air yang di perbolehkan oleh Permenkes No. 492/MenKes/PER/IV/2010 yaitu $0 / 100 \mathrm{ml}$ air.

\section{PEMBAHASAN}

Air merupakan salah satu jenis sumber daya alam yang di perlukan 
untuk mendukung kehidupan oleh hampir semua makhluk hidup yang mendiami permukaan bumi. Oleh sebab itu, keberadaan sumber daya air harus di lindungi agar tetap dapat diandalkan untuk mendukung kehidupan baik bagi manusia maupun makhluk hidup lainnya. Air sumur gali banyak digunakan oleh masyarakat terutama masyarakat pedesaan karena selain pembuatannya yang mudah dan dapat dilakukan oleh masyarakat itu sendiri dengan peralatan yang sederhana dan biaya yang murah. Sehingga banyak masyarakat pedesaan menggunakan air sumur gali sebagai sumber air bersih. Air sumur gali tersebut digunakan oleh masyarakat untuk kebutuhan sehari-hari baik untuk minum, memasak, mandi maupun mencuci. Air sumur gali sangat mudah terkontaminasi oleh bakteribakteri patogen, salah satunya adalah bakteri Coliform.

Menurut

Permenkes No.492/MenKes/PER/IV/2010 pasal 1 ayat 1 menyatakan bahwa "air minum adalah air yang melalui proses pengolahan atau tanpa proses pengolahan yang memenuhi syarat kesehatan dan dapat langsung di minum". Air minum aman bagi kesehatan apabila memenuhi persyaratan fisika, mikrobiologis dan radioaktif. Uji laboratorium terhadap sampel air sumur gali yang bertujuan untuk mengidentifikasi coliform pada air sumur gali dengan menggunakan pemeriksaan MPN (Most Probable Number). Dalam pemeriksaan MPN ini menggunakan media LB (Lactosa Broth) dan BGLB (Brilliant Green Bile Lactosa Broth).
Hasil analisis bakteri coliform pada sampel air sumur gali di wilayah penelitian bervariasi yaitu pada sampel 1 sebanyak 920 MPN/100 ml air dimana gambaran fisik sumur pada sampel 1 yaitu sumur berjarak 1 meter dari wc, 5 meter dari septik tank dan 8 meter dari kanal, memiliki lantai yang kedap air, kadang-kadang timba di simpan pada lantai dan di sekitar sumur di gunakan untuk mencuci. Sampel 2 sebanyak 1600 MPN/100 ml air dimana gambaran fisik sumur berada di luar rumah, memiliki lantai yang tidak kedap air, dinding sumur berlumut, sumur berjarak 2 meter dari wc, 3 meter dari septik tank dan 9 meter dari kanal. disekitar sumur di gunakan untuk mencuci dan terkadang timbanya berada di lantai. Pada sampel 3 sebanyak 180 MPN/100 ml air dimana gambaran fisik sumur pada sampel 3 yaitu memiliki lantai yang kedap air, sumur berada di dalam rumah, berjarak 5 meter dari wc, 8 meter dari kanal dan 6 meter dari septik tank. Sampel 4 sebanyak 1600 MPN/100 ml air dimana gambaran fisik sumur pada sampel 4 yaitu disekitar sumur digunakan untuk mencuci, timba sering di simpan di lantai, memiliki lantai yang tidak kedap air, berjarak 2 meter dari wc, 4 meter dari septik tank dan 8 meter dari kanal. pada sampel 5 sebanyak 920 MPN/100 ml air dimana gambaran fisik sumur yaitu berjarak 2 meter dari wc, 5 meter dari septik tank dan 11 meter dari kanal. serta di sekitar sumur digunakan untuk mencuci. Sampel 6 sebanyak 350 MPN/100 ml air dimana gambaran fisik sumur pada sampel 6 yaitu memiliki lantai yang kedap air, berjarak 3 meter dari 
wc, 3 meter dari septik tank, 11 meter dari kanal dan sumur berada di dalam rumah. Pada sampel 7 sebanyak 1600 MPN/100 ml air dimana gambaran fisik sumur pada sampel 7 yaitu jarak sumur dengan wc sebanyak 3 meter dan 2 meter dari septik tank serta di sekitar sumur digunakan untuk mencuci. Sampel 8 sebanyak 1600 MPN/100 ml air dimana gambaran fisik sumur pada sampel 8 yaitu sumur berjarak 2 meter dari wc, 4 meter dari septik tank dan sumur berada di dekat kandang bebek. Pada sampel 9 sebanyak 280 MPN/100 ml air dimana gambaran fisik sumur pada sampel 9 yaitu sumur berada di dalam rumah, memiliki lantai yang kedap air, berjarak 4 meter dari wc, 4 meter dari septik tank dan 11 meter dari kanal. sampel 10 sebanyak 110 MPN/100 ml air dimana gambaran fisik sumur pada sampel tersebut yaitu sumur berada di dalam rumah, memiliki lantai yang kedap air, berjarak 4 meter dari wc, 3 meter dari septik tank dan 11 meter dari kanal.

Hasil tersebut mengindikasikan bahwa air telah tercemar oleh bakteri coliform yang dapat menyebabkan penyakit-penyakit saluran pencernaan. Dari 10 sampel air yang telah di periksa semuanya tidak memenuhi syarat karena semua sampel berada di atas ambang baku mutu air yang di perbolehkan oleh Permenkes.. Hal ini disebabkan karena sumur gali pada umumnya berdekatan dengan wc, septik tank, dan kanal. Dimana kanal tersebut di jadikan sebagai tempat pembuangan sampah baik sampah rumah tangga maupun binatang yang telah mati. Disamping itu kepadatan penduduk di wilayah tersebut sangat tinggi.
Dimana rata-rata jarak sumur $<5$ meter dari pembuangan tinja dan $<11$ meter dari kanal. serta keadaan sumur yang tidak tertutup dan lantai yang tidak kedap air sehingga air buangan meresap kembali kedalam sumur yang akan mempermudah terjadinya kontaminasi bakteri. Meskipun pada tempat pengambilan sampel mempunyai komposisi tanah liat tetap memperhatikan jarak sumur gali dengan sumber pencermaran. Sebab Hal tersebut dapat berpengaruh terhadap cemaran coliform pada sumur gali penduduk yang sangat berdampak pada kualitas air.

Apabila air yang telah terkontaminasi oleh coliform dikonsumsi tanpa pengolahan yang baik, maka dampak gangguan kesehatan akan terjadi kepada para konsumen sehingga di perlukan pengelolaan air yang baik dan benar.

\section{KESIMPULAN}

Berdasarkan hasil penelitian yang telah dilakukan pada tanggal $14-26$ Juli 2016 di Laboratorium Bakteriologi Analis Kesehatan Politeknik Kesehatan Makassar terhadap 10 sampel air sumur gali yang berada di sekitar Kanal Kelurahan Mataallo Kecamatan Bajeng Kabupaten Gowa yang telah di uji secara bakteriologi di peroleh hasil MPN coliform yaitu 110 MPN/100 ml, $180 \mathrm{MPN} / 100 \mathrm{ml}, 280$ MPN/100 ml, $350 \mathrm{MPN} / 100 \mathrm{ml}, 920$ MPN/100 ml dan $1600 \mathrm{MPN} / 100 \mathrm{ml}$ air dan tidak memenuhi standar yang telah di keluarkan oleh Permenkes No. 492/MenKes/PER/IV/2010 yaitu 0/100 ml air. 


\section{SARAN}

1. Disarankan kepada masyarakat agar lebih memperhatikan jarak sumur gali dengan sumber pencemaran coliform seperti jamban, septik tank, limbah rumah tangga dan kanal serta memenuhi syarat pembuatan sumur gali

2. Diharapkan kepada peneliti selanjutnya untuk melakukan penelitian tentang pemeriksaan fisika atau kimia air sumur gali

\section{DAFTAR PUSTAKA}

Akhadi. M, 2014. Isu lingkungan Hidup: Mewaspadai Dampak Kemajuan Teknologi dan Polusi Lingkungan Global yang Mengamcam Kehidupan. Yogyakarta : Graha Ilmu

Fardiaz. S , 1993. Analisis Mikrobiologi Pangan. Jakarta : Raja Grafindo Persada

Novel Sasika Sinta, Wulandari. A, Safitri Ratu, 2010. Praktikum Mikrobiologi Dasar. Jakarta : Trans Info Media

Pusat laboratorium kesehatan, 1991.

Petunjuk Pemeriksaan Mikrobiologi Air. Jakarta : Departemen Kesehatan

Sumantri. A , 2010. Kesehatan Lingkungan. Jakarta : Kencana

Suriawiria Unus. 2005. Air dalam Kehidupan dan Lingkungan yang Sehat. Bandung : PT Alumni

Suripin. 2004. Pelestarian Sumber Daya Tanah dan Air. Yogyakarta : Andi
Waluyo Lud. 2009. Mikrobiologi Lingkungan. Malang : Ummpress

http://Noviaki.10jambi.Wordpress.co $\mathrm{m} / 2011 / 04 / 30 /$ pengambilansampel- air-padasumur-gali-secara-fisik. Diakses pada tanggal 20 mei 2016 